\title{
Determination of Local-Area Distribution and Relocation of Radioactive Cesium in Trees from Fukushima Daiichi Nuclear Power Plant by Autoradiography Analysis
}

\author{
Fuminori SAKAMOTO $^{1}$, Toshihiko OHNUKI ${ }^{1, *}$, Naofumi KOZAI ${ }^{1}$, \\ Shinya YAMASAKI ${ }^{1}$, Zenko YOSHIDA ${ }^{2}$ and Kenji NANBA ${ }^{3}$ \\ ${ }^{1}$ Japan Atomic Energy Agency, 2-4 Shirane, Shirakata, Tokai-mura, Naka-gun, Ibaraki 319-1195, Japan \\ ${ }^{2}$ ATOX Co. Ltd., 161-2 Muramatsu, Tokai-mura, Naka-gun, Ibaraki 319-1112, Japan \\ ${ }^{3}$ Fukushima University, 1 Kanayagawa, Fukushima-shi, Fukushima 960-1296, Japan
}

\begin{abstract}
The local area distribution and relocation of radioactive cesium deposited in trees after the 2011 tsunami-related accident at the Fukushima Daiichi Nuclear Power Plant (FDNPP) have been studied by measuring the spatial distribution of cesium on/in trees by autoradiography analysis. Samples of trees were collected from places located between 4 and $55 \mathrm{~km}$ from FDNPP approximately 2, 8, 20, and 22 months after the accident. The autoradiography analyses of Cryptomeria japonica, Torreya nucifera, and Thujopsis dolabrata var. hondae samples collected approximately 2 and 8 months after the accident showed that radioactive Cs was mainly distributed as spots on the branches and leaves of the trees emerged before the accident, and was detected in negligible amounts in new branch and leaves that emerged after the accident. On the contrary, radioactive Cs was detected at the outermost tip of the branches in the trees collected 20 months after the accident. Morus alba samples collected 22 months after the accident contained radioactive Cs inside and outside their stems, even though no radioactive Cs was detected in their roots, strongly suggesting that a certain amount of radioactive Cs was translocated from the outside to the inside of stems. These results indicate that the distribution of radioactive Cs deposited on/in the trees gradually changes with time (scale: year).
\end{abstract}

KEYWORDS: radioactive fallout, radioactive Cs, translocation, migration, autoradiography

\section{Introduction}

A large amount of nuclides produced by nuclear fission (hereinafter referred to as "radionuclides") was released into the environment due to the reactor melt down and hydrogen explosion at the Tokyo Electric Power Company (TEPCO) Fukushima Daiichi Nuclear Power Plant (hereinafter referred to as the " $1 \mathrm{~F}$ accident") that occurred on March 11, 2011. The total amount of radioactive $\mathrm{Cs}$ and radioactive $\mathrm{I}$ released in the atmosphere was $10^{16}-10^{17} \mathrm{~Bq}$, according to the report by Chino et al ${ }^{1)}$. and Brumfiel ${ }^{2)}$. Of the radioactive I, ${ }^{131} \mathrm{I}$ decayed out within

\footnotetext{
* Corresponding author, E-mail: ohnuki.toshihiko@jaea.go.jp

DOI : 10.15669/fukushimainsights. Vol.4.204

(C) 2021 Atomic Energy Society of Japan. All rights reserved.

Originally published in Transactions of the Atomic Energy Society of Japan (ISSN 1347-2879), Vol. 12, No. 4, p.257-266

(2013) in Japanese. (Japanese version accepted: May 24, 2013)
} 
about two months of the $1 \mathrm{~F}$ accident due to its short half-life of approximately eight (8) days; therefore, the residual radioactive nuclides in the environment are mainly ${ }^{134} \mathrm{Cs}$ (half-life of approximately 2.1 years) and ${ }^{137} \mathrm{Cs}$ (half-life of approximately 30 years) ${ }^{3)}$.

Decontamination activities were conducted at a good pace for the purpose of removing radioactive Cs from contaminated areas ${ }^{3)}$. Through such decontamination activities, a large amount of waste materials were packed in flexible container bags (hereinafter referred to as "flecons") and stored in temporary storage places. Given this situation, the environmental influence of radioactive Cs contained in the decontamination waste should be evaluated. To evaluate any leakage of radioactive Cs from decontamination waste requires recognition of the conditions surrounding radioactive $\mathrm{Cs}$ in the flecons. As trees and grasses were discarded from home gardens, back hills, and fruit farms and then packed with other decontamination wastes in flecons, there is concern of relocation of radioactive $\mathrm{Cs}$ in the environment through solubilization due to the decomposition of trees and grasses.

Sakamoto et al. conducted an autoradiograph analysis of the local distribution of the deposited radionuclides in the trees and grasses, targeting samples taken two months after the $1 \mathrm{~F}$ accident ${ }^{4}$. Their study demonstrated that the radioactive Cs that deposited on trees showed higher concentrations on the stem and leaves that had emerged before the $1 \mathrm{~F}$ accident, while almost no relocation took place to the branches and leaves that emerged after the deposition, but the major part of the radioactive Cs that deposited on pasture grass and rice stubs accumulated there in situ. Similar results were found in research by Tanaka et al. that analyzed C. japonica ${ }^{5}$.

The long-term relocation of radioactive $\mathrm{Cs}$ is being studied in Chernobyl. Reports show that radioactive $\mathrm{Cs}$ is accumulated in biological bodies such as trees and mushrooms ${ }^{6}$. On the other hand, based on study of the distribution of radioactive Cs by atomic bomb tests, it is reported that $80 \%$ of radioactive Cs has been distributed in the soil layer near the ground surface as deeply as $5 \mathrm{~cm}$ in pine forest, with the remainder distributed deeper in the soil or in the plants ${ }^{7}$. The radioactive Cs deposited on tree crowns in Fukushima was considered to be leached by rain or snow and thereby joined in the environmental cycle. However, it is considered that the relocation of radioactive $\mathrm{Cs}$ accumulated in trees has not been completely clarified.

To measure the distribution of radioactive Cs in tree samples, the trees should be divided into several parts to obtain adequate spatial resolution. Higher spatial resolution is achieved by dividing into small pieces, which leads to decreased measurement count. Unfortunately, as a result, spatial resolution may be limited to $10 \mathrm{~mm}$. In contrast, autoradiography analyzes the distribution of radionuclides by placing the samples directly on imaging plates sensitive to radiation ${ }^{8}$. Autoradiography's shortcoming is its inability to identify the radionuclides because it cannot distinguish between the types and energies of radiation detected. Among the radionuclides in fallout in Fukushima-Prefecture, the radionuclides that were detected after May are, as mentioned above, ${ }^{134} \mathrm{Cs}$ and ${ }^{137} \mathrm{Cs}$. Thus it is possible to study the behavior of radioactive Cs accumulated in the trees after the $1 \mathrm{~F}$ accident by measuring the local distribution to an accuracy of well under $10 \mathrm{~mm}$.

This report details the autoradiography study of the samples of trees collected (1) in May and November 2011, and December 2012 in Iitate-Village Kita-Soma-County Fukushima-Prefecture, (2) in May 2012 and February 2013 in Nihonmatsu-City Fukushima-Prefecture, (3) in October 2011 in Date-City Fukushima-Prefecture, and (4) in December 2012 in Okuma-Machi Futaba-County Fukushima-Prefecture Also, the relocation of radioactive Cs within a tree following precipitation was investigated, and the leaching of radioactive $\mathrm{Cs}$ from decontamination wastes including grasses was studied. 


\section{Experimental Methodology}

\section{Sampling and Preparation of Samples}

The collected trees were Japanese cedar (C. japonica), Japanese torreya (T. nucifera), var. hondae makino (T. dolabrata var. hondae), peach (Prunus percica) and mulberry (M. alba). $C$. japonica, Torreya and var. makino are evergreen needle-leaved trees. For the purpose of observing any variation with aging, evergreen trees that would not experience defoliation were selected. Peach and M. alba are defoliating trees, but were selected because there was concern about the effects on fruit trees. For C. japonica, sampling of developed male and female flowers was conducted. The samples of Torreya branches were selected from those with branches and leaves that were considered to have grown before the 1F accident in 2011, in the spring of 2011 and in the spring of 2012. The samples of var. hondae makino were taken from the branches and leaves. Peach stems (diameter approximately $25 \mathrm{~mm}$ ) and $M$. alba stems (diameter approximately $50 \mathrm{~mm}$ ) were cut into round slices and the cross sections were used as samples (peach stem cross section and $M$. alba stem cross section, respectively). The underground root portion (diameter approximately $50 \mathrm{~mm}$ ) of $M$. alba was also cut into round slices and used as a sample (mulberry root cross section sample). For peach trees, the peeled stem bark sample (peach bark sample) and vertically torn twig sample (twig sample) were used. Furthermore, the Parmeliaceae (Parmotrema tinctorum) that lived on the torreya stem in Nagadoro Iitate-Village was collected. For madake (Phyllostachys bambusoides), samples (bamboo sample) of stem cut into round slices and tender shoots (bamboo shoot sample) were used. The samples and the location and time of sampling are summarized in Table 1. The number of samples was one (1) for each because the sampling was conducted in areas that were difficult to revisit.

\section{Autoradiography Measurement}

The system used for autoradiography measurement (hereinafter abbreviated as "AR") was the Bioimaging Analyzer BAS2500 (Fuji Film/Japan). The space resolution of the imaging plate (IP) was $0.05 \mathrm{~mm}$. After exposing the collected/prepared sample for 24-72 hours on the IP, the area on which the radioactive sample had lain was imaged using an IP reading and analyzing device.

In the images acquired, the higher the radiation dose, i.e., the higher the concentration of radioactive nuclides, the more intense the blackness. Furthermore, a unique analysis of two images with different intensities is possible by changing the intensity gradient of the radioactivity dose. During a measurement, to avoid contamination of the IP by the sample, the sample was covered with a thin film of polyvinylidene chloride. After completion of the measurement, an optical photo of the sample, which was covered with the polyvinylidene chloride film, was taken. Additionally, the radioactivity of the sample was measured using a $\mathrm{NaI}$ scintillation counter (Aloka TCS161) before conducting the AR measurement. Furthermore, the radioactive nuclides contained in some of the samples were measured using the Ge semiconductor $\gamma$ ray spectrum analysis system (ORTEC). The M. alba stem samples and root samples were crushed at the same position as AR measurements were made, and were encapsulated in a $1 \mathrm{~L}$ Marinelli container, and then the contained radioactive nuclides were measured with $\gamma$ ray spectrum analysis (NaI scintillation spectrometer ATOMEXAT1320A). The radioactive doses measured using the scintillation counter for all samples were twice as high as background, so it was understood that there was almost no influence from ${ }^{40} \mathrm{~K}$. The grid in the AR and photos is $2.54 \mathrm{~cm}$ $\times 2.54 \mathrm{~cm}$ on the IP. 
Table 1 Tree samples and their parts analyzed by autoradiography, with places of origin and collection dates

\begin{tabular}{|c|c|c|c|c|}
\hline Sample & Sample Portion & Location of Sampling & Time of Sampling & $\begin{array}{c}\text { Distance from } 1 \mathrm{~F} \\
(\mathrm{~km})\end{array}$ \\
\hline C. japonica & Branches and leaves & May, 2011 & $\begin{array}{l}\text { Nagadoro, Iitate- } \\
\text { Village }\end{array}$ & 33 \\
\hline C. japonica & Branches and leaves & Nov., 2011 & $\begin{array}{l}\text { Nagadoro, Iitate- } \\
\text { Village }\end{array}$ & 33 \\
\hline C. japonica & Branches and leaves & Nov., 2012 & $\begin{array}{l}\text { Nagadoro, Iitate- } \\
\text { Village }\end{array}$ & 33 \\
\hline C. japonica & Branches and leaves & Dec., 2012 & $\begin{array}{c}\text { Kodate, Okuma- } \\
\text { Machi }\end{array}$ & 4 \\
\hline $\begin{array}{l}\text { T. dolabrata var. } \\
\text { hondae }\end{array}$ & Branches and leaves & Oct., 2011 & Ryozen, Date-City & 50 \\
\hline $\begin{array}{l}\text { T. dolabrata var. } \\
\text { hondae }\end{array}$ & Branches and leaves & Nov., 2012 & $\begin{array}{l}\text { Nagadoro, Iitate- } \\
\text { Village }\end{array}$ & 33 \\
\hline T. nucifera & Branches and leaves & Dec., 2012 & $\begin{array}{c}\text { Kodate, Okuma- } \\
\text { Machi }\end{array}$ & 4 \\
\hline P. persica & Branches & Oct., 2011 & Oguni, Date-City & 55 \\
\hline P. persica & Stem & Oct., 2011 & Oguni, Date-City & 55 \\
\hline P. persica & Epidermis & Oct., 2011 & Oguni, Date-City & 55 \\
\hline M. alba & Stem & Feb., 2013 & $\begin{array}{c}\text { Tosawa, Nihonmatsu- } \\
\text { City }\end{array}$ & 43 \\
\hline M. alba & Roots & Feb., 2013 & $\begin{array}{c}\text { Tosawa, Nihonmatsu- } \\
\text { City }\end{array}$ & 43 \\
\hline M. alba & Branches and leaves & May., 2012 & $\begin{array}{c}\text { Takatsuki, } \\
\text { Nihonmatsu-City }\end{array}$ & 47 \\
\hline Parmeliaceae & & May., 2011 & $\begin{array}{l}\text { Nagadoro, Iitate- } \\
\text { Village }\end{array}$ & 33 \\
\hline P. bambusoides & Stem & May., 2012 & $\begin{array}{l}\text { Kohata, Ninonmatsu- } \\
\text { City }\end{array}$ & 47 \\
\hline Bamboo Shoot & Tender Shoot & May., 2012 & $\begin{array}{l}\text { Kohata, Ninonmatsu- } \\
\text { City }\end{array}$ & 47 \\
\hline
\end{tabular}

\section{Results}

Autoradiography of branches and leaves of $C$. japonica collected in Iitate-Village in May 2011 (Figure 1) yielded a slight blackening from the branches and leaves, and dark spots all over the range of $C$. japonica. The growth of tender shoots at the tip of branches is seen in the photograph of branches and leaves. On the other hand, in the AR images, no specific accumulation of radioactive Cs on the male flower was observed. Similarly, in the AR images of branch and leaf samples collected in Iitate-Village in November 2011 (Figure 2), an increase in blackness and density of black spots was observed all over as in Figure 1. In the optical photographs, the growth of a male flower is observed in the area surrounded by a light blue circle, but no obvious concentration of radioactive $\mathrm{Cs}$ on any male flower is observed in the AR images. In the AR images, large and dense black spots are visible in the area surrounded by a blue circle. Although it is not clearly visible in the optical photos, the brown female flowers were identified, i.e. the female flowers that grew before the $1 \mathrm{~F}$ accident. This suggests that radioactive Cs was deposited directly on the male flower during precipitation. Although the results are not shown, the black spots were observed all over on the C. japonica sample collected in Date-City on October 2011 similarly to Figure 2.

The presence of scattered black spots was observed in the analysis of $C$. japonica branches and leaves collected in Iitate-Village in November 2012 (Figure 3). Furthermore, it was 

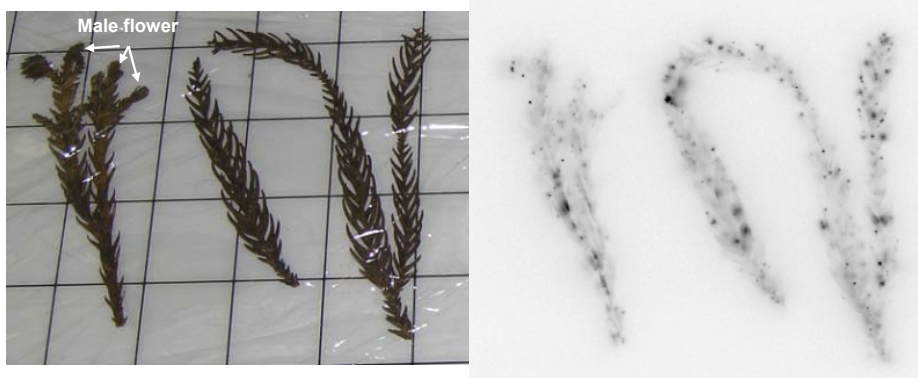

Figure 1 Autoradiograph image (left) and optical photograph (right) of branch and leaves of C. japonica collected in Iitate 2 months after the FDNPP accident

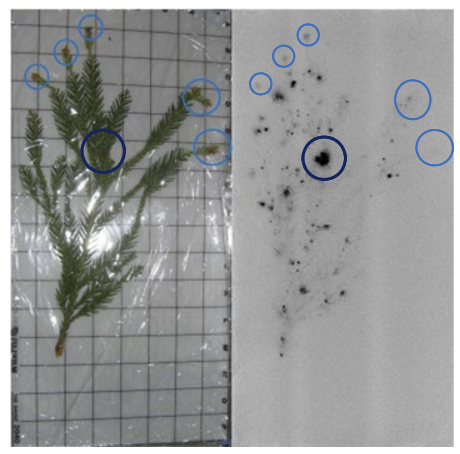

Figure 2 Autoradiograph image (left) and optical photograph (right) of branch and leaves of C. japonica collected in Iitate 8 months after the FDNPP accident. Light blue circles show a male flower that emerged before the FDNPP accident, and the dark blue shows one female flower that emerged before the FDNPP accident.

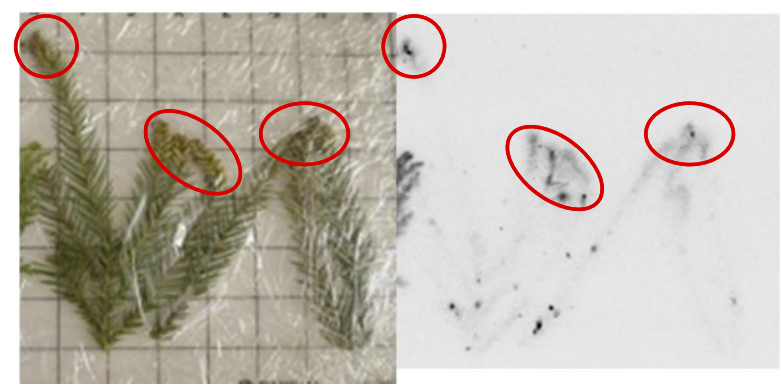

Figure 3 Autoradiograph image (left) and optical photograph (right) of branch and leaves of $C$. japonica collected in Iitate 20 months after the FDNPP accident. Red circles show a male flower that emerged after the FDNPP accident.

observed that the blackness at the tip of twigs surrounded by a red line is darker than that in other areas. In the optical photos, a male flower was found in the area, showing that the concentration of radioactive Cs on the male flower is higher than in the branches and leaves at the tip portion, although the blackness on the male flower is less than that of the black spots. In the AR analysis conducted on the C. japonica branches and leaves collected at Kodate, Okuma-Machi in December 2012 (Figure 4), the AR image shows the dense black spots in 
the female flower area surrounded by a blue line in the optical photo. In this area, black spots are smaller than those of the female flower. As the female flower areas are brown and assumed to have grown before the $1 \mathrm{~F}$ accident, the radioactive $\mathrm{Cs}$ is considered to have been directly deposited and to have remained in the area of deposition. The blackness density is lower in the upper part than in the female flower area, i.e., the branches and leaves in the tip area, and again a dense black area is recognized in the tip area of branches and leaves. As male flowers are found in the area surrounded by a red line, the density of radioactive Cs is comparatively higher in the male flower. Furthermore, in the areas where a male flower is not found, surrounded by a yellow-green line in the optical photo, a similar level of blackness is seen in the AR image as in the male flower area.

The AR analysis results on T. dolabrata var. hondae collected in Date-City in October 2011 are shown in Figure 5. The black spots appear in all areas of branches and leaves in the AR image of T. dolabrata var. hondae. However, in the T. dolabrata var. hondae collected in Iitate-Village in November 2012, as shown in the AR image (Figure 6), almost no black spots were found, but dense black areas were found in the tip area of twigs.
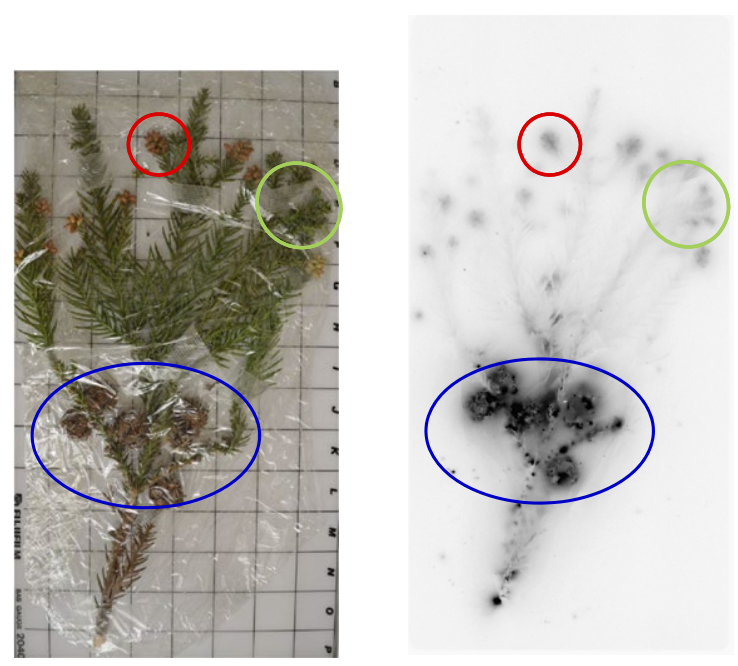

Figure 4 Autoradiograph image (left) and optical photograph (right) of branch and leaves of C. japonica collected in Ookuma 21 months after the FDNPP accident. The blue circle shows a female flower that emerged before the FDNPP accident, and the red circle shows one male flower that emerged before the FDNPP accident. The green circle indicates the outermost tip of the branch.
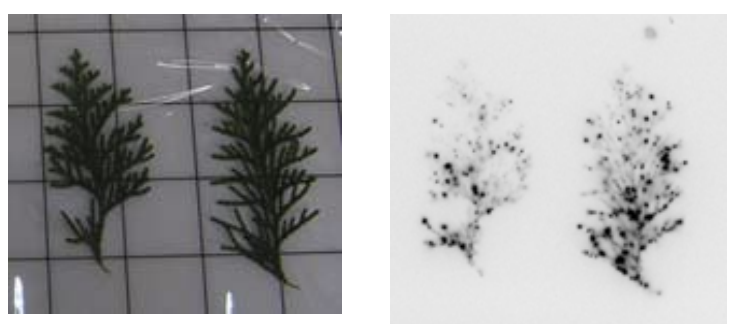

Figure 5 Autoradiograph image (right) and optical photograph (left) of branch and leaves of T. dolabrata var. hondae collected in Date 7 months after the FDNPP accident. 
In the AR results (Figure 7) from T. nucifera collected in Okuma-Machi in December 2012, the branches and leaves that had grown before the 1F accident (area surrounded with a blue line in the photo), those grown in 2011 after the $1 \mathrm{~F}$ accident (area surrounded with a blue dot-anddash line) and those grown in 2012 (area surrounded with a blue dotted line) were observed. In the AR images, many black dots were found in the area that had grown before the $1 \mathrm{~F}$ accident. The more recent the year of growth, the fewer black dots were found. Almost no such dots were found in the area that grew in 2012. This indicates with high probability that most of the radioactive $\mathrm{Cs}$ that directly deposited from the $1 \mathrm{~F}$ accident remained on the branches and leaves where deposited. The blackness on branches and leaves that had grown after the $1 \mathrm{~F}$ accident does not show noteworthy concentration in any area, but rather a uniform distribution.

In the AR analysis of a twig sample of P. persica collected in Date-City in October 2011 (Figure 8), black spots are visible on the bark of twigs that had grown before the $1 \mathrm{~F}$ accident. In contrast, on the twigs that grew after the $1 \mathrm{~F}$ accident, although black spots are visible on the branches near the stem surrounded by a black line, they are not visible at all in other areas. Measurement of the ${ }^{137} \mathrm{Cs}$ concentration using a Ge semiconductor detector on crushed twig samples separated into those that had been grown before and after the $1 \mathrm{~F}$ accident showed that the branches and leaves grown before the $1 \mathrm{~F}$ accident yielded $30,000 \mathrm{~Bq} / \mathrm{kg}$ and those grown after the $1 \mathrm{~F}$ accident just $500 \mathrm{~Bq} / \mathrm{kg}$. The AR analysis of a $P$. persica stem section and bark
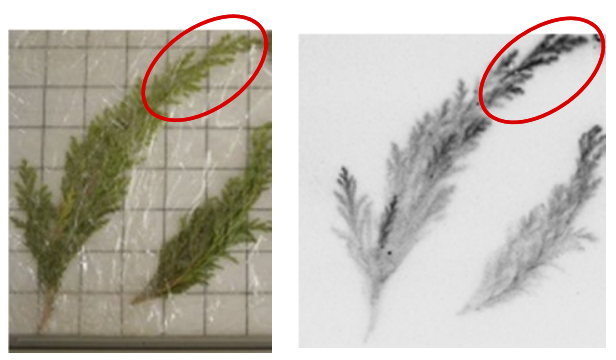

Figure 6 Autoradiograph image (right) and optical photograph (left) of branch and leaves of T. dolabrata var. hondae collected in Iitate 20 months after the FDNPP accident.
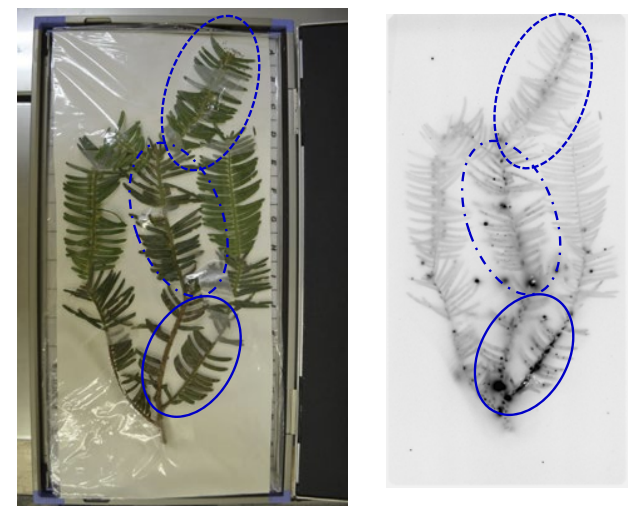

Figure 7 Autoradiograph image (right) and optical photograph (left) of branch and leaves of T. nucifera collected in Ookuma 22 months after the FDNPP accident. The blue solid oval shows the branch portion that emerged before the FDNPP accident, the blue dash-dot oval the branch portion that emerged after the FDNPP accident, and the blue dashed oval the branch that emerged 1 year after the FDNPP accident. 
sample (Figure 9) showed black spots on the stem bark, but almost no spots inside of the stem (Figure $9(a, b)$ ). In the AR image of the P. persica bark sample (Figure $9(\mathrm{~d})$ ), there were black spots on the bark as well as a dark area that spread over the surface with a similar blackness, as indicated with an arrow.

These results indicate that there is radioactive Cs on the stem bark that is deposited like spots and that is also seen as a dark area.

The AR analysis results for a $M$. alba stem section sample and $M$. alba root section sample collected in Nihonmatsu-City in February 2013 are shown in Figure 10. The AR image of the stem sample shows high grayness in the area without the sample. In the area without the sample, background $\alpha$ or $\beta$ radiation was detected, while the area with the sample

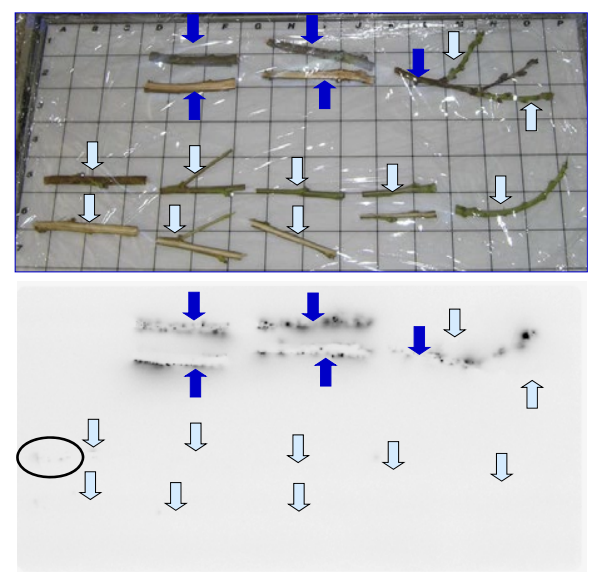

Figure 8 Autoradiograph image (lower) and optical photograph (upper) of branches of $P$. percica collected in Date 20 months after the FDNPP accident. Blue arrows show branches that emerged before the FDNPP accident, and light blue arrows branches that emerged after the FDNPP accident; the black circle shows spotted deposits of radioactive Cs on a branch that emerged after the FDNPP accident.

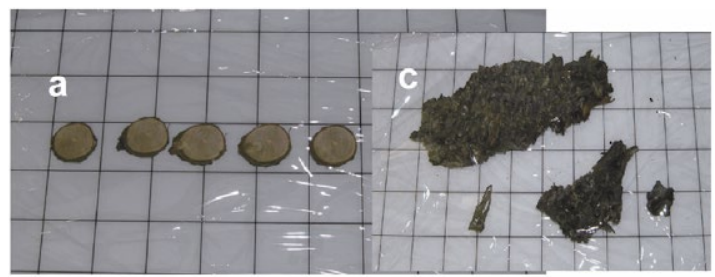

b

d

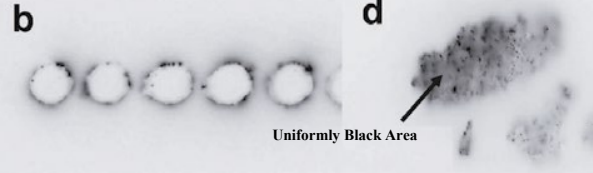

Figure 9 Autoradiograph images (b, d) and optical photographs (a, c) of cross sections of branches (a, b) and bark (c, d), respectively, of $P$. percica collected in Date 20 months after the FDNPP accident. 
did not show grayness, presumably due to the shielding effect of the samples. Black spots were observed on the stem bark area in the AR image (Figure 10 (b)) of the M. alba stem section sample (Figure 10 (a)). However, no black spots were seen in the AR image (Figure 10 (d)) of the cross section of the $M$. alba sample (Figure 10 (c)). Comparing the blackness of the inside of stem and root in the AR images shows a slightly higher grayness of the inside of the stem section sample than the inside of the root section sample.

As the AR images of stem and root were acquired with identical exposure times, they indicate the transport of radioactive Cs into the inside of the stem. Measurements indicate that order of ${ }^{137} \mathrm{Cs}$ concentration is: stem bark $(500 \mathrm{~Bq} / \mathrm{kg})>$ stem inside $(150 \mathrm{~Bq} / \mathrm{kg})>\operatorname{root}(18 \mathrm{~Bq} / \mathrm{kg})$. These results agreed with AR analyses, and supported the near absence of radioactive Cs in the root area, and the accumulation of radioactive $\mathrm{Cs}$ in the stem bark and inside. From the AR analysis result (Figure 11) on the branches and leaves of $M$. alba collected in Nihonmatsu-City in May 2012, a uniform distribution of radioactive Cs in the twig area was confirmed by the uniformly high blackness in the twig area. In the leaf area as well, the uniform distribution of radioactive Cs was indicated by the uniform black areas recognized similarly on twigs.

AR analysis of foliaceous lichen (P. tinctorum) collected in Iitate-Village in May 2011 (Figure 12) shows many black spots on the lichen that forms the yellow-green area in the optical photos, and black surface areas appear. On the other hand, with regard to the blackness of the bark areas appearing as brown in the optical photos, the blackness is thinner compared to
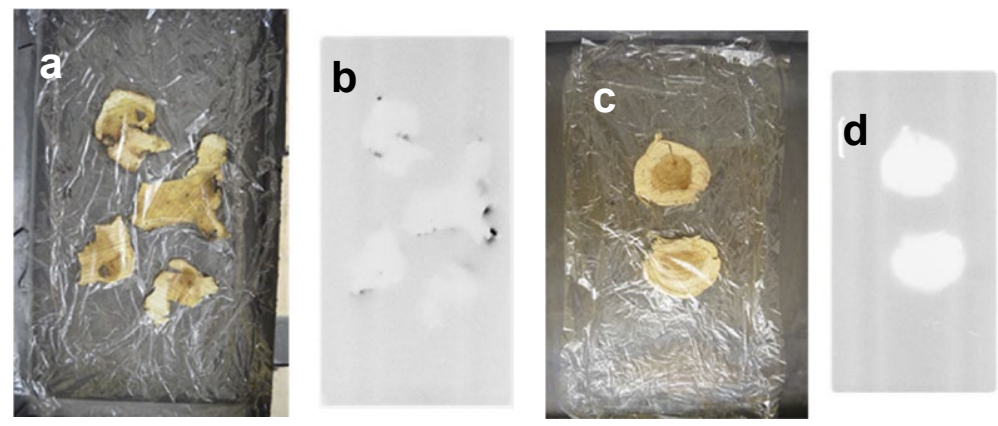

Figure 10 Autoradiograph images (b, d) and optical photographs (a, c) of cross sections of branches (a, b) and root (c, d), respectively, of M. alba collected in Nihonmatsu 23 months after the FDNPP accident
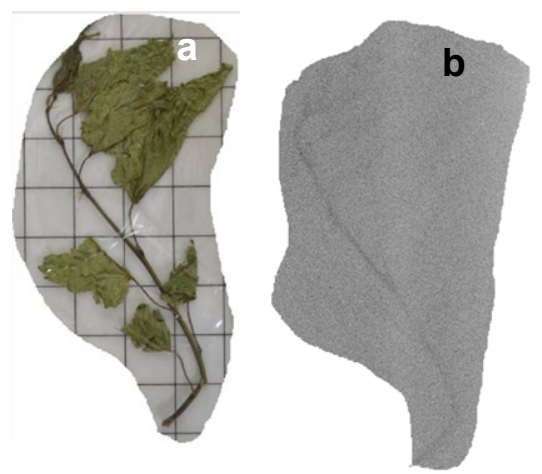

Figure 11 Autoradiograph image (b) and optical photograph (a) of branch and leaves of $M$. alba collected in Nihon-matsu 15 months after the FDNPP accident 
that in the foliaceous lichen areas. This indicates a higher concentration of radioactive Cs on foliaceous lichen than on the bark area.

$\mathrm{AR}$ analyses were conducted on the bamboo samples and bamboo shoot samples collected in Nihonmatsu-City in May 2012 using the round slice bamboo section samples (a, b), bamboo shoot section samples (c, d), the bamboo shoot vertical section samples (e, d), and bamboo shoot bark samples $(\mathrm{g}, \mathrm{h})$. The AR analysis showed (Figure 13) that the inside of the stem of bamboo section samples was uniformly black (Figure 13 (b)). The uniform blackness was also observed on the bamboo shoot section samples and the bamboo shoot vertical section samples, although the blackness was thinner than that of the bamboo section samples.

The AR images of bamboo shoot vertical section samples showed a uniform blackness of the plate and the internode of the bamboo shoot. This indicated that radioactive Cs had accumulated in the bamboo stems. As the AR image of the bamboo shoot bark sample shows, the bark area is blackened as well.

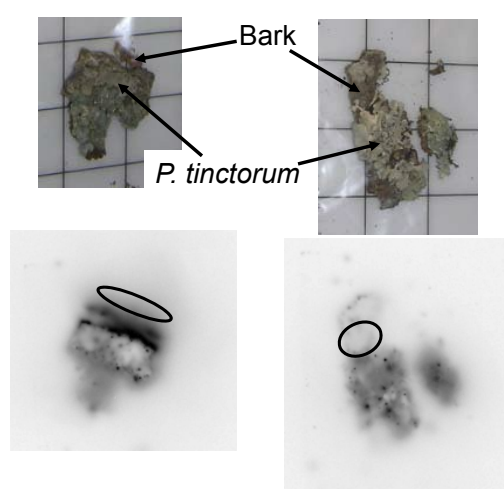

Figure 12 Autoradiograph image (lower) and optical photograph (upper) of lichen P. tinctorum collected in Iitate 2 months after the FDNPP accident

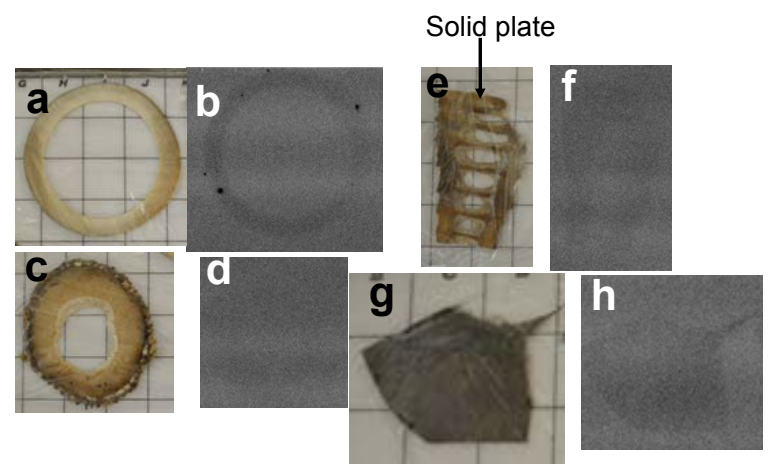

Figure 13 Autoradiograph images (b, d, f, h) and optical photographs (a, c, e, g) of cross section of internode $(\mathrm{a}, \mathrm{b})$ of $P$. bambusoides, vertical cross section of the sheath of a bamboo shoot $(\mathrm{e}, \mathrm{f})$, cross section of the internode of a sheath of a bamboo shoot, and the peel of bamboo shoot $(\mathrm{g}, \mathrm{h})$ 


\section{Discussion}

\section{Relocation of Radioactive Cs in a Tree}

The AR analyses conducted on the tree samples collected two months after the $1 \mathrm{~F}$ accident in March 2011 showed that the radioactive Cs deposited on trees was more concentrated on the stems and leaves that were present before the $1 \mathrm{~F}$ accident ${ }^{4}$. As explained above, in the $C$. japonica samples collected two months after the $1 \mathrm{~F}$ accident, no accumulation on the male flower was observed and a heterogeneous distribution of black spots of radioactive Cs was confirmed. The area of the spots in an AR image will vary not only according to the size of the radionuclide deposit, but also to its radioactivity and the AR exposure time. Hence, radioactive Cs was directly deposited on the trees like an aerosol, and deposited on the trees as spots.

In the AR analyses of the trees of $C$. japonica and T. dolabrata var. hondae collected six months after the $1 \mathrm{~F}$ accident, most of the radioactive Cs had a spotty distribution on trees (Figure 2). Furthermore, in the C. japonica sample collected in Okuma-Machi in December 2012, radioactive Cs was present on the female flower and branches and leaves that had grown before the $1 \mathrm{~F}$ accident (Figure 4). The samples in which the black spots were also found are C. japonica, P. persica, and T. dolabrata var. hondae sampled in Date-City in October 2011 (Figures 5, 8, and 9 respectively). Because the distance of the sampling locations from $1 \mathrm{~F}$ was $\sim 4 \mathrm{~km}$ (Okuma-Machi) and $\sim 55 \mathrm{~km}$ (Date-City), it was elucidated that radioactive Cs adhered as spots on the trees grown before the $1 \mathrm{~F}$ accident, not depending on the type of tree nor the distance from $1 \mathrm{~F}$. Because the same spotty adhesion of radioactive Cs was found in the $C$. japonica sampled six months after the $1 \mathrm{~F}$ accident, the distribution is considered to be a specific distribution of radioactive $\mathrm{Cs}$ that deposited directly on $C$. japonica, soon after the $1 \mathrm{~F}$ accident.

The distribution of radioactive $\mathrm{Cs}$ in the sample of $C$. japonica that was collected more than one year after the $1 \mathrm{~F}$ accident was completely different from that collected after six months. As shown in the AR analysis of $C$. japonica, the ratio of spots of radioactive Cs decreases in the branches and leaves that grew after the $1 \mathrm{~F}$ accident, and in the specific local distribution in the tips of branches and leaves or on male flowers (Figures 3 and 4). This distribution is different from the spotty distribution observed on the tree surface. Thus, it is considered that the distribution of radioactive Cs was not due to direct adherence on the tree surfaces. One of the possible pathways, such as by the adhesion of soil contaminated with radioactive $\mathrm{Cs}$, has been considered, but in this case the expected distribution is spots on the tips of branches and leaves. This hypothesis agrees with the scenario of a uniform aerial distribution like that observed in AR images of $C$. japonica. It is reasonable to conclude that the distribution of radioactive Cs was not on the stem surface but inside of $C$. japonica. Consequently, it is conceivable that the radioactive Cs deposited on the stem surface was absorbed into the inside of stem, and relocated to the tips of branches and leaves. This trend is seen not only in C. japonica, but also in $T$. dolabrata var. hondae (Figure 6).

On the other hand, the distribution in the branches and leaves of T. nucifera is different from that of C. japonica and T. dolabrata var. hondae. On the branches and leaves of T. nucifera, the radioactive Cs shows a spotty deposition on the branches and leaves that had grown before the $1 \mathrm{~F}$ accident, and a uniform distribution on the branches and leaves that had grown after the $1 \mathrm{~F}$ accident. Similarly, the uniform distribution in the branches and leaves that had grown after the $1 \mathrm{~F}$ accident is seen on M. alba. These results indicate two distribution patterns for the radioactive $\mathrm{Cs}$ in the branches and leaves that had grown after the $1 \mathrm{~F}$ accident, i.e., its concentration in the tip area in C. japonica, and its uniform distribution in T. nucifera and M. alba.

In the AR analyses of $M$. alba, the spotty adhesion of radioactive Cs on the bark as well as 
the distribution in the stem was observed on the M. alba stem that was collected approximately two years after the $1 \mathrm{~F}$ accident (Figure 10), while radioactive Cs was not present in the root area. These results indicate a low likelihood of absorption of radioactive Cs present in the stem via the roots. Kozai et al. studied the chemical species of radioactive Cs in the soil of Iitate-Village using the selective extraction method and clarified that more than $70 \%$ of radioactive Cs in the soil is in a chemical form that does not exchange cations ${ }^{9}$. This result points to problems for the idea of direct uptake of radioactive Cs from soil into the root shown in the AR analysis of a root of $M$. alba. Hasegawa et al. conducted the experiment of attaching ${ }^{137} \mathrm{Cs}$ to a leaf of radish and reported that a portion of ${ }^{137} \mathrm{Cs}$ is absorbed via the phylloplane ${ }^{10)}$. Tagami et al. measured the radioactive $\mathrm{Cs}$ on the leaves of evergreen trees and deciduous trees in Chiba-City and reported that several tens to several hundreds of $\mathrm{Bq} / \mathrm{kg}$ were detected ${ }^{11)}$. The results of our research indicated the relocation of radioactive $\mathrm{Cs}$ in $M$. alba from epidermis to the inside by translocation.

P. persica showed that radioactive Cs was distributed both evenly and in a spotty manner on the bark of trees that had grown before the $1 \mathrm{~F}$ accident (Figure 9). This result indicates that the radioactive Cs distributed as spots relocated into the bark surface during the six months after the $1 \mathrm{~F}$ accident. As almost no radioactive Cs was detected inside the stem of $P$. persica, it is considered that the radioactive Cs deposited on the bark remained in position. This implies that most of the deposited radioactive Cs stayed in the epidermis of $P$. persica trees. In contrast, as shown in Figure 8, almost no radioactive Cs was detected in the tree stems of those that had grown before or after the $1 \mathrm{~F}$ accident. This indicates that the radioactive Cs stayed in the bark of $P$. persica for at least six months after the $1 \mathrm{~F}$ accident.

The radioactive Cs was also distributed on the surface of foliaceous lichen (Figure 12). The blackness in the AR image of the foliaceous lichen is denser than that of the bark in Figure 12, indicating the accumulation of radioactive $\mathrm{Cs}$ on the inside of the lichen. Similarly to the above mentioned C. japonica, the even distribution also indicates the relocation of radioactive Cs to the inside of the lichen. Such accumulation of radioactive Cs in lichen in Austria was reported at a level 120 times higher than that before the accident of Chernobyl ${ }^{12)}$. The high accumulation of radioactive Cs in foliaceous lichen is not only due to the spot adhesion, but also the accumulation on the inside.

As the C. japonica sample shows accumulation of radioactive $\mathrm{Cs}$ in the male flower area, radioactive $\mathrm{Cs}$ is considered to have been accumulated in the region of active growth in a tree. Based on analyses conducted on pine trees during the twelve years after the accident at Chernobyl, it was pointed out that the radioactive Cs was concentrated in the tender shoot area with predominant growth, together with stable $\mathrm{Cs}^{13)}$. The results of our research on $C$. japonica and $T$. dolabrata var. hondae indicate that the radioactive $C s$ was accumulated in the active growth areas on the tips of twigs by translocation from the bark to the inside of the stem in the second year after the $1 \mathrm{~F}$ accident. It is considered that the concentration of radioactive Cs in the area of bamboo shoot nodes and sheathes in the AR images of the bamboo shoot vertical section sample was caused by the selective concentration of radioactive Cs in the areas of predominant growth. On the other hand, in T. nucifera and M. alba, the radioactive Cs showed spatial distribution. Furthermore, some $P$. persica trees showed stagnated radioactive $\mathrm{Cs}$ in the bark even a half year after the $1 \mathrm{~F}$ accident. Mori et al. refers to the accumulation on the inside of trees by translocation based on the significant increase in the radioactive Cs concentration in the tree sap of Rhus vernicifera ${ }^{14)}$.

Thus, the redistribution of the radioactive Cs deposited on the bark is not the same among different species of plants. In the future, it will be necessary to clarify the differences in the redistribution behavior in different plant species after the $1 \mathrm{~F}$ accident. 


\section{Chemical forms of Radioactive Cs in Trees Containing Decontamination Waste}

To evaluate the influence of radioactive Cs on the environment when the decontamination waste is stored or disposed of, leakage and migration of radioactive Cs from the decontamination waste must be predicted. As the migration behavior of radioactive Cs from decontamination waste depends on its chemical form, we should identify the chemical forms of radioactive Cs in decontamination waste.

Decontamination waste is considered to contain soil and vegetation. Some waste includes material whose decay and its prevention must be considered ${ }^{3)}$. In the soils contained in the decontamination waste, multiple chemical forms of radioactive $\mathrm{Cs}$ were found to be present ${ }^{9,15)}$. However, almost no analysis has been conducted on plants. Our results indicate a time-dependent change of the chemical form of radioactive Cs spread by the $1 \mathrm{~F}$ accident. That is, radioactive Cs exists in spots on the surface of branches and leaves that grew before the $1 \mathrm{~F}$ accident, but radioactive Cs was found to be present inside of the stem of branches and leaves that grew during the year following the $1 \mathrm{~F}$ accident.

To study the solubility of the deposited radioactive Cs on the bark surface, a desorption experiment was conducted using $1 \mathrm{M} \mathrm{CH}_{3} \mathrm{COOH}$ solution to accelerate its eluviation by rainwater on the branches and leaves that grew before the $1 \mathrm{~F}$ accident. The results of the desorption experiment on two T. nucifera samples are shown in Table 2. The radioactive Cs content of Samples 1 and 2 differ by 1 digit, but almost no radioactive $\mathrm{Cs}$ was desorbed with the $1 \mathrm{M} \mathrm{CH}_{3} \mathrm{COOH}$ solution. This result indicates that the leach-out due to the desorption of radioactive Cs from the tree by the infiltration of rainwater is extremely low. The AR analysis of the T. nucifera sample processed with the $1 \mathrm{M} \mathrm{CH}_{3} \mathrm{COOH}$ solution showed unchanged spotty distribution of radioactive Cs. Relocation of radioactive Cs deposited on the plant surface to the inside of the plant and to the soil layer by absorption in foliage or weathering has been reported ${ }^{10)}$. Kawabata et al. reported that more than $80 \%$ of solid aerosol deposition of Cs on the Raphanus sativus var. sativus was relocated to the outside of the plant ${ }^{16}$. These results, corroborated by our results, imply that the eluviation of radioactive Cs by weathering is extremely low for any trees contained in the decontamination wastes.

On the other hand, because the radioactive Cs contained in the branches and leaves that grew after the $1 \mathrm{~F}$ accident is present inside the tree, it is considered more difficult to desorb than the radioactive Cs that exists in the bark. As it is implied that the Co captured inside of a microbial cell is more difficult to be removed than Co adsorbed on cell surface ${ }^{17)}$, the desorption of radioactive $\mathrm{Cs}$ accumulated inside the tree is considered to be less than the radioactive Cs on the bark surface. Other living organisms such as algae or lichens inhabit plants as well, and lichen is known to condense radioactive $\mathrm{Cs}^{18)}$. AR analysis of lichens indicated the presence of radioactive $\mathrm{Cs}$ in the form of spots on the surface, and also accumulated within the plant. Radioactive Cs in such chemical forms may exhibit different desorption behavior from the radioactive Cs distributed in the bark or inside the tree. Furthermore, as there are various microorganisms living in decontamination waste, the radioactive Cs may be desorbed through cracking by the microorganisms in the tree. It is considered that the time required for cracking is different for

Table 2 Radioactive Cs desorbed from an old branch of $T$. nucifera by a $1 \mathrm{M} \mathrm{CH}_{3} \mathrm{COOH}$ solution

\begin{tabular}{cccc}
\hline \multirow{2}{*}{ T. nucifera Sample } & \multicolumn{3}{c}{ Radioactivity $\left(\mathrm{Bq} \cdot \mathrm{g}^{-1}\right)$} \\
\cline { 2 - 4 } & Before Treatment & After Treatment & In $1 \mathrm{M} \mathrm{CH}_{3} \mathrm{COOH}$ solution \\
\hline 1 & $6.6 \times 10^{2}$ & $6.6 \times 10^{2}$ & $1.0 \times 10^{-2}$ \\
\hline 2 & $1.8 \times 10^{3}$ & $1.8 \times 10^{3}$ & $2.2 \times 10^{-1}$ \\
\hline
\end{tabular}


the bark and inside the tree. Furthermore, it is reported that the microorganisms themselves preserve the radioactive $\mathrm{Cs}^{19,20)}$. Consequently, for the evaluation of the leaching behavior of radioactive $\mathrm{Cs}$ from any tree, it will be necessary to identify the type of tree, time of sampling, and presence of organisms, such as lichen, on the tree surface.

\section{Summary}

Using autoradiography, the local area distribution of radioactive Cs was measured in trees sampled in different locations and at different time periods since the $1 \mathrm{~F}$ accident, and the behavior of radioactive Cs contained in the radioactive fallout in the tree was studied. As a result, the following has been clarified:

- The distribution in the tree was mainly in the form of spots on the branches and leaves that grew before the $1 \mathrm{~F}$ accident, and this form persisted for approximately a year after the $1 \mathrm{~F}$ accident.

- The spotty distribution of radioactive Cs has been clarified as a typical form of distribution of radioactive Cs fallout, and is not dependent on the type of tree nor the distance from $1 \mathrm{~F}$.

- One year after the $1 \mathrm{~F}$ accident, the presence of radioactive Cs contained inside the trees was observed, instead of just the spotty radioactive Cs on the branches and leaves. Three types of distribution were observed in contaminated trees: (1) accumulation in the tip area of male flowers, branches, and leaves such as C. japonica or T. dolabrata var. hondae, (2) uniform distribution in the tree such as T. nucifera or M. alba, and (3) preservation in the bark of $P$. persica.

These results indicate that the radioactive Cs that fell out on the trees varied its chemical forms with time. Consequently, it is necessary to study the contaminated types in the trees, time of sampling, and the presence of living organisms, such as lichens on the tree surface.

We express our gratitude to Dr. Hirofumi Tsukada of the Institute for Environmental Sciences for the valuable advice we received from him while we worked on completing this research paper. Part of this research was conducted with the aid of Grants-in-Aid for Scientific Research by MEXT, subject No. 25289355.

\section{References}

1) M. Chino, H. Nakayama, H. Nagai, H. Terada, G. Katata, H. Yamazawa, "Preliminary estimation of release amounts of 131I and 137Cs accidentally discharged from the Fukushima Daiichi Nuclear Power Plant into the atmosphere," J. Nucl. Sci. Technol., 48, 1129-1134 (2011).

2) A. Omoto, ICAPP2011 Special Japan Session: Presentation (2-6 May, 2011 Nice, France). file is available at, http://www.aesj.or.jp/information/fnpp201103/icapp2011_Omoto_WEBrevision20110517.pdf

3) Ministry of the Environment, Off-site Decontamination Measures, available at, http://josen.env.go.jp/en/.

4) F. Sakamoto, T. Ohnuki, N. Kozai, S. Igarashi, S. Yamasaki, Z. Yoshida, S. Tanaka, "Local area distribution of fallout radioanuclides from Fukushima Daiichi Nuclear Power Plant determined by autoradiography analysis," Trans. At. Energy Soc. Jpn., 11, 1-7 (2012). [In Japanese]

5) K. Tanaka, H. Iwatani, A. Sakaguchi, Y. Takahashi, Y. Onda, "Local distribution of radioactivity in tree leaves contaminated by fallout of the radionuclides emitted from the Fukushima Daiichi Nuclear Power Plant," J. Radioanal. Nucl. Chem., 295, 2007-2014 (2013).

6) S. Yoshida, Y. Muramatsu, A. M. Dvornik, T. A. Zhuchenko, I. Linkv, "Equilibrium of radiocesium with stable cesium within the biological cycle of contaminated forest ecosystems," J. Environ. Radioact., 75 301-313 (2004).

7) N. Yamagata, S. Matsuda, M. Chiba, "Radioecology of cesium-137 and strontium-90 in a forest," $J$. Radiat. Res., 10, 107-112 (1969). 
8) F. Sakamoto, T. Ohnuki, T. Fujii, H. Iefuji, "Response of Saccharomyces cerevisiae to heavy element stress: lead vs. uranium," Geomicrobiol. J., 27, 240-244 (2010).

9) N. Kozai, T. Ohnuki, M. Arisaka, M. Watanabe, F. Sakamoto, S. Yamasaki, M. Jiang, "Chemical states of fallout radioactive Cs in the soils deposited at Fukushima Daiichi Nuclear Power Plant accident," $J$. Nucl. Sci. Technol., 49, 473-478 (2012), (Doi: 10.1080/00223131.2012.677131).

10) H. Hasegawa, H. Tsukada, H. Kawabata, Y. Chikuchi, Y. Takaku, S. Hisamatsu, "Effect of the counter anion of cesium on foliar uptake and translocation," J. Enviorn. Radioact., 100, 54-57 (2009).

11) K. Tagami, S. Uchida, N. Ishii, S. Kagiya, "Translocation of radiocesium from stems and leaves of plants and the effect on radiocesium concentrations in newly emerged plant tissues," J. Enviorn. Radioact., 111, 65-69 (2012).

12) G. Heinrich, K. Oswald, H. J. Muller, "Lichens as monitors of radiocesium and radiostrontium in Australia," J. Enviorn. Radioact., 45, 13-27 (1999).

13) S. Yoshida, M. Watanabe, A. Suzuki, "Distribution of radiocesium and stable elements within a pine tree," Radiat. Prot. Dosim., 146, 1-3, 326-329 (2011).

14) S. Mori, A. Hirato, K. Tanoi, K. Takeda, T. Yamakawa, H. Nakanishi, "Radioactive cesium flow in Rhus vernicifera," Soil Sci. Plant Nutri., 58, 611-617 (2012).

15) K. Tanaka, Y. Takahashi, A. Sakaguchi et al., "Vertical Pro-files of Iodine-131 and Cesium-137 in Soils in Fukushima Prefecture related to the Fukushima Daiichi Nuclear Power Station Accident," Geochem. $J ., 46,73-76$ (2012).

16) K. Kawabata, H. Hasegawa, H. Tsukada, Y. Takaku, S. Hisamatsu, "Behavior of Trace Elements on Leaf Surfaces of Crop Plants," Annu. Rep. Inst. Environ. Sci., 20-24 (2010). [in Japanese]

17) N. Kozai, T. Ohnuki, F. Sakamoto, Y. Suzuki, K. Tanaka, H. Iefuji, T. Sakai, "Accumulation of Co in yeast cells under metabolically active condition - Implication for role of yeast in migration of radioactive Co-," J. Nucl. Sci. Technol., 48, 1206-1213 (2011).

18) G. Heinrich, K. Oswald, H. J. Muller, "Lichens as monitors of radiocesium and radiostrontium in Australia," J. Enviorn. Radioact., 45, 13-27 (1999).

19) R. A. Olsen, E. Joner, L. R. Bakken, Soil Fungi and the Fate of Radiocaesium in the Soil Ecosystemda Discussion of Possible Mechanisms Involved in the Radiocaesium Accumulation in Fungi and the Role of Fungi as a Cs-sink in the Soil. In: Desmet, G., Nassimbeni, P., Belli, M. (Eds.), Transfer of Radionuclides in Natural and Semi-natural Environments. Elsevier Applied Science, London, New York, pp. 657-663 (1990).

20) B. H. Fawaris, K. J. Johanson, "Fractionation of ${ }^{137} \mathrm{Cs}$ in coniferous forest soil in central Sweden," Sci. Total Environ., 170, 221-228 (1995). 